\title{
Hospitals should be exemplars of healthy workplaces
}

\section{It is time for \\ hospitals \\ to become \\ stronger \\ advocates \\ for health, \\ wellbeing \\ and the \\ environment}

Lesley M Russel

BSc(Hons), BA, PhD

Matthew HR Anstey

MBBS, MPH, FCICM

Susan Wells

MBChB, MPH, PhD

1 Australian Primary Health

Care Research Institute

Canberra, ACT.

2 Sir Charles Gairdner Hospital Perth, WA.

3 University of

Auckland, Auckland

New Zealand.

lesley.russell@

anu.edu.au

doi: 10.5694/mjal4.01437

Podcast with

Dr Lesley Russell

available at mja.com.au/

multimedia/podcasts $\mathrm{n}$ ancient Egypt and Greece, temples functioned as centres of medical advice and healing. Hospitals are now the temples of the health care world, performing modern-day miracles in treating illness and injury. However, the gains in life expectancy made in the past century owe as much to public health interventions as to hospital-based care, ${ }^{1}$ and in the 21 st century the world faces a different set of challenges arising from chronic diseases. Tackling the root causes of chronic disease such as poor nutrition, lack of exercise, poor housing, contaminated environments, smoking and alcohol misuse - requires more than doctors, nurses and prescription pads.

Hospitals see the consequences and bear the burden of failures to deal with the social determinants of health. Given their unique position in the health care system, it is time for hospitals to become stronger advocates for health, wellbeing and the environment. As major employers and flagship health care organisations, hospitals can influence the norms of the communities they serve by adopting model policies and practices that promote the health of patients, visitors, employees, students and trainees.

Increasingly, hospitals are required to take into consideration the health status of the communities they serve in designing and delivering their services. In the United States, this is recognised in the community health needs assessment requirements imposed on charitable hospitals by the Affordable Care Act. ${ }^{2}$ A similar push has occurred for Australian local hospital networks to ensure delivery of services based on local needs, ${ }^{3}$ and for over a decade, each New Zealand district health board has been required to create a picture of the health status of its regional population. ${ }^{4}$ We argue that these efforts will not succeed unless and until hospitals themselves are seen as showing the way in health promotion.

While quality improvement initiatives often focus on systems, processes and outcomes of care, we believe there are structural changes that seem to be low-hanging fruit. Many of these changes are relatively small and low-cost but they mean hospitals can better deliver health and wellbeing alongside health care. They include reorienting hospital policies to ensure they provide healthy, ecologically sound and sustainable environments; an increased focus on promoting health and prevention; and fostering interpersonal safety.

\section{Hospitals as stewards of sustainability and the environment}

The health of the environment affects the health of the population. Hospitals are energy- and resource-intensive, and the World Health Organization notes three benefits of making them "climate-friendly". ${ }^{5}$ First, health benefits

\section{Summary}

- As major employers and flagship health care organisations, hospitals can influence the norms of the communities they serve by adopting model policies and practices that promote the health of patients, visitors, employees, students and trainees.

- Hospitals must become healthy workplaces in every sense and extend their role to focus on health and wellness, not just illness.

- Reorienting hospital policies can:

- ensure the provision and stewardship of healthy, ecologically sound and sustainable environments;

- increase the focus on promoting health and prevention;

- foster interpersonal safety; and

- improve workplace safety.

- Such efforts deliver improvements in health outcomes and savings in hospital budgets.

will accrue from reducing carbon emissions and other pollutants created by waste disposal. Second, reducing energy usage and waste will reap economic benefits. Third, there is the positive societal and environmental influence of the health sector fulfilling its obligation to "do no harm". To achieve climate-friendly hospitals, the WHO suggests seven focus areas: energy efficiency, green building design, alternative energy production, transportation, food sustainability, waste reduction and water conservation.

With their high energy use, health services account for more than half of greenhouse gas emissions in the public sectors of large states like New South Wales. ${ }^{6}$ Estimates from the United Kingdom suggest that the travel of patients, staff and visitors to and from hospitals contributes up to $20 \%$ of the hospitals' carbon footprint. ${ }^{7}$ Plastics account for a third of hospital waste, and a quarter of that is estimated to be polyvinyl chloride (PVC). In Australia, there is a nascent program for hospitals and dialysis units to recycle as many as possible of the 50 million intravenous fluid bags and lengths of PVC tubing used every year, rather than send them to landfill. Done well, this can be a cost-neutral waste management solution. ${ }^{8}$

A healthy hospital should measure its environmental footprint and take action to reduce it through energy and water management, waste reduction, the purchase of environmentally friendly products and the provision of transportation alternatives. Hospital administrators should think about how they could cooperate with local government and public transport services to best promote cycling, walking and public transport use. ${ }^{9}$

Sustainability strategies are possible even for established buildings, and increasing energy costs should make this 
an imperative. In the US state of Pennsylvania, Geisinger Health System implemented a successful energy reduction program that annually achieved more than US $\$ 6.3$ million in savings, reduced greenhouse gas emissions by $80 \%$ and reduced water use by $20 \%{ }^{10}$ In an example of a countrywide approach, the UK's National Health Service (NHS), as part of its carbon reduction strategy, has set an initial target for NHS institutions to reduce their emissions by $10 \%$ (from 2007 levels) by $2015 .^{11}$

As a positive example of hospitals departing from their traditional roles, 13 of the largest American health systems have come together to create the Healthier Hospitals Initiative (http://healthierhospitals.org). Acknowledging the large amount of resources consumed by health care services and their substantial purchasing power, this program asks its members to commit to improving their energy usage, providing healthier food options and purchasing safer and less toxic products, and then measures their success. Considerable savings have already been achieved by members of this initiative and could exceed US\$5.4 billion over 5 years..$^{12}$ However, despite the excellent work by sentinel organisations, including the international group Health Care Without Harm (http:// noharm.org), hospitals that have made this a focus remain in the minority.

\section{Health promotion must be a core dimension of} hospital services

The aim of health-promoting hospitals, a concept that has been in existence for over 20 years, ${ }^{13}$ is to reorient health services away from focusing solely on curative care towards a more holistic approach that encompasses the principles of health promotion for patients, visitors, staff and trainees.

Despite the drama and urgency usually involved, a hospital admission for illness or accident is also an opportunity for preventive interventions. Patients, families and carers are more likely to pay attention when the risk factor (eg, smoking, obesity, excessive alcohol consumption, family violence) is proximate to the lung disease, heart attack, road accident or injury that has brought them into acute care. ${ }^{14}$ Failure to tackle such risk factors and to take advantage of the "teachable moment" the presentation offers increases the likelihood that the presentation will reoccur. However, a 2010 literature review found a dearth of published, high-level research on health-promoting hospitals, ${ }_{1}^{15}$ reflecting the low priority given to research into health promotion in health care systems generally and in acute care specifically.

Even if implementing a formal health promotion framework is not possible, there are a range of areas where hospitals can lead by example. It is important for hospital patients, visitors and employees to have healthy and affordable food and beverages and an environment that encourages physical activity and connectivity. ${ }^{16}$ In addition, hospitals should facilitate breastfeeding and lactation support, access to tobacco cessation interventions including nicotine replacement therapy, and substance and alcohol misuse programs in a non-judgemental environment.

There are other prevention and health promotion recommendations that are essential, yet are too often poorly implemented. These include handwashing, influenza vaccinations, workplace violence and injury prevention, and the safe handling of dangerous chemicals and radioactive waste.

\section{Workplace injury, violence and bullying}

Recent reports highlight the importance of mental health and wellbeing in the hospital workplace. Research shows that nurses in particular are at high risk of work-related injury and stress-related illness. ${ }^{17,18}$ The latter is linked to work overload and role-based factors, such as lack of power, role ambiguity and role conflict. ${ }^{17}$ A study commissioned by the Australian Safety and Compensation Council found the most commonly reported problems were musculoskeletal injuries, stress, bullying and infection. $^{18}$

Most unintentional injuries can be avoided and psychological distress can be reduced through appropriate prevention and early intervention strategies. Particular emphasis needs to be given to preventing and managing aggression and violence towards hospital staff — an increasingly common situation, especially in emergency departments ${ }^{19}$ — and bullying. These are complex problems that require multifaceted solutions, not all of which are within the purview of hospitals. But they cannot be ignored, as both workplace violence and bullying influence job performance, retention and stress, ${ }^{20}$ and these in turn influence quality and safety.

There is evidence that bullying in hospitals does not just happen between supervisors and their staff or between different professions, but is also peer-to-peer. ${ }^{21}$ Fostering a safety culture means more than drawing a line between acceptable and unacceptable interpersonal behaviour; it encompasses a culture of trust where staff are encouraged to speak up about their concerns and are comfortable about reporting mistakes and near-misses. Indeed, improving the workplace safety culture has been associated with improved outcomes for staff and patients. ${ }^{22}$ Safe work environments are also necessary for best-practice clinical learning, a key hospital function. ${ }^{23}$

\section{Conclusion}

Hospitals must become healthy workplaces in every sense. This is an integral part of the push for quality and safety in clinical care and also contributes to the triple bottom line for health care: better patient experience of care; better population health through improved social and environmental impacts; and better financial performance. ${ }^{24}$

Although hospitals have healing as their core value, they contribute to the burden of illness and injury by selling junk food, consuming enormous amounts of energy, generating waste that is simply disposed of in landfill, 
and through poor workplace practices. We argue that hospitals must be fully involved in the health agenda, leading the way in their communities by promoting health, providing healthy and safe workplaces and working towards environmental sustainability. They must exploit their respected status for the benefit of the communities they serve and lead the way for others to follow. The benefits will be returned quickly in terms of better health outcomes for patients and the public, workforce recruitment and retention, cleaner environments and cost savings.

Competing interests: No relevant disclosures.

Provenance: Not commissioned; externally peer reviewed.

References are available online at www.mja.com.au. 
1 Centers for Disease Control and Prevention (CDC). Ten great public health achievements - United States, 1900-1999. Morb Mortal Wkly Rep 1999; 48: 241-243. http://www.cdc.gov/ mmwr/preview/mmwrhtml/00056796.htm (accessed Oct 2014).

2 Robert Wood Johnson Foundation. What's new with community benefit? Health Policy Snapshot Issue Brief 2012; (Oct): 1-2. http://www.rwjf.org/content/dam/farm/reports/ issue_briefs/2012/rwjf402124 (accessed Oct 2014).

3 Health Reform Queensland. Community and consumer engagement in local hospital networks. Consultation Paper No. 5, Version 1. Brisbane: Queensland Health, 2010. http:// www.qnu.org.au/_data/assets/pdf_file/0003/237747/QHCommunity-and-Consumer-Engagement-Paper.pdf (accessed Oct 2014).

4 Coster $\mathrm{G}$. Health needs assessment for New Zealand: background paper and literature review. Wellington: NZ Ministry of Health, 2000. http://www.moh.govt.nz/notebook/ nbbooks.nsf/0/32871d4ccb9f8202cc256a0d00725le9/\$FILE/ HNAbackground.pdf (accessed Oct 2014).

5 World Health Organization, Health Care Without Harm. Healthy hospitals, healthy planet, healthy people: addressing climate change in healthcare settings. Discussion draft 2009. http://www.who.int/globalchange/publications/healthcare_ settings/en (accessed Oct 2014).

6 New South Wales Auditor-General. Performance audit: building energy use in NSW public hospitals. Sydney: Audit Office of NSW, 2013. http://www.audit.nsw.gov.au/ ArticleDocuments/271/01_Building_Energy_Use_NSW_Public_ Hospitals_Full_Report.pdf.aspx (accessed Apr 2015).

7 NHS Sustainable Development Unit. NHS England carbon emissions: carbon footprint modelling to 2020. London: NHS, 2009. http://www.sduhealth.org.uk/documents/resources/ Carbon_Footprint_emmissions_modelling_2009.pdf (accessed Oct 2014).

8 Vinyl Council Australia. PVC Recovery in Hospitals. http:// vinyl.org.au/about-pvc/pvc-products/pvc-in-healthcare/pvcrecovery-in-hospitals (accessed Oct 2014).

9 Pencheon D. Health services and climate change: what can be done? J Health Serv Res Policy 2009; 14: 2-4.

10 Neuner AR. Leading your healthcare organization toward energy efficiency: a call to action. Premier Safety Institute, 2011. http://www.premiersafetyinstitute.org/wp-content/ uploads/2014/01/Energy-whitepaper-04-2011.pdf (accessed Oct 2014).

1 Carbon reduction in the NHS: a role for finance. HFMA Briefing 2009; (Dec). http://www.sduhealth.org.uk/documents/ publications/HFMA_Briefing_carbon_reduction.pdf (accessed Oct 2014).

12 Kaplan S, Sadler B, Little K, et al. Can sustainable hospitals help bend the health care cost curve? New York: The Commonwealth Fund, 2012. http://www.commonwealthfund. org/publications/issue-briefs/2012/nov/sustainable-hospitals (accessed Dec 2014).

13 International Network of Health Promoting Hospitals \& Health Services. About HPH. http://www.hphnet.org/index. php?option=com_content\&view=article\&id=22\&ltemid $=4$ (accessed Apr 2015).

14 Spirito A, Monti PM, Barnett NP, et al. A randomized clinical trial of a brief motivational intervention for alcohol-positive adolescents treated in an emergency department. J Pediatr 2004; 145: 396-402.

15 McHugh C, Robinson A, Chesters J. Health promoting health services: a review of the evidence. Health Promot Int 2010; 25: 230-237.

16 Wiseman A, Boothe A, Reynolds M, Belay B. Healthy hospital choices: recommendations and approaches from an expert panel. Atlanta: US Centers for Disease Control and Prevention, 2010. http://www.cdc.gov/nccdphp/dnpao/hwi/docs/ healthyhospbkweb.pdf (accessed Oct 2014).

17 Moustaka E, Constantinidis TC. Sources and effects of workrelated stress in nursing. Health Sci J 2010; 4: 210-216.

18 Vecchio N, Scuffham PA, Hilton M, Whiteford HA. Work-related injury among the nursing profession: an investigation of modifiable factors. J Adv Nurs 2011; 67: 1067-1078.

19 Gilchrist H, Jones SC, Barrie L. Experiences of emergency department staff: alcohol-related and other violence and aggression. Australas Emerg Nurs J 2011; 14: 9-16.

20 Di Martino V. Workplace violence in the health sector. Relationship between work stress and workplace violence in the health sector. Geneva: ILO/ICN/WHO/PSI, 2003. http://www.who.int/violence_injury_prevention/violence/ interpersonal/WVstresspaper.pdf (accessed Oct 2014).

21 Kaminski M, Kettering Sincox A. Workplace bullying in health care: peer-to-peer bullying of nurses. Proceedings of the 16th International Labour and Employment Relations Association World Congress; 2012 Jul 2-5; Philadelphia, USA. http://ilera2012.wharton.upenn.edu/refereedpapers/ kaminskimichelle.pdf (accessed Oct 2014).

22 The Evidence Centre. Evidence scan: does improving safety culture affect patient outcomes? London: The Health Foundation, 2011. http://www.health.org.uk/public/ cms/75/76/313/3078/Does\%20improving\%20safety\%20 culture\%20affect\%20outcomes.pdf?realName=fsu8Va.pdf (accessed Apr 2015).

23 Darcy Associates. Best practice clinical learning environments within health services for undergraduate and early-graduate learners: final report. Melbourne: Victorian Department of Health, 2009. http://docs.health.vic.gov.au/docs/doc/3E 0389B583131A55CA2578810010694C/\$FILE/BPCLE\%20 Development\%20Phase\%20Report.pdf (accessed Nov 2014).

24 Stiefel M, Nolan K. A guide to measuring the triple aim: population health, experience of care, and per capita cost. IHI Innovation Series white paper. Cambridge, Mass: Institute for Healthcare Improvement, 2012. http://www.jvei.nl/wpcontent/uploads/A-Guide-to-Measuring-the-Triple-Aim.pdf (accessed Oct 2014). 